\title{
Collodion Dosage Form
}

National Cancer Institute

\section{Source}

National Cancer Institute. Collodion Dosage Form. NCI Thesaurus. Code C149373.

Liquid preparation usually containing pyroxylin in a mixture of ether and ethanol. When applied to the skin, the preparation forms a flexible film on the site of application. 